\title{
Accidental PUVA burns, vitiligo and atopic diathesis resulting in prurigo nodularis: a logical but undocumented rarity
}

\author{
Prurigo nodular induzido por queimaduras acidentais por PUVA, vitiligo e \\ diátese atópica: uma raridade lógica, mas não documentada
}

\author{
Shyam Bhanushankar Verma ${ }^{1}$
}

Uwe Wollina $^{2}$

\begin{abstract}
Vitiligo is a dreaded disease in India due to its social and cultural consequences. PUVA and PUVAsol are the main treatment modalities for vitiligo vulgaris. To the best of our knowledge, this is the first case of accidental PUVA burns eventuating in prurigo nodularis lesions to be reported in a female patient who was undergoing home PUVA therapy. The itch is so prominent and disabling that the focus of the patient has shifted from treating her vitiligo to ameliorating the pruritus.

Keywords: PUVA Therapy; Prurigo; Pruritus; Vitiligo

Resumo: O vitiligo é uma doença temida na Índia por suas consequências sociais e culturais. As principais modalidades de tratamento do vitiligo vulgar são as terapias PUVA e PUVAsol. Pelo que sabemos, este é o primeiro relato de caso de prurigo nodular induzido por queimaduras acidentais por PUVA em paciente do sexo feminino em tratamento domiciliar com PUVA. O prurido é tão intenso e incapacitante que o foco da paciente passou do vitiligo à busca constante pela melhora do prurido.

Palavras-chave: Prurido; Prurigo; Terapia PUVA; Vitiligo
\end{abstract}

\section{INTRODUCTION}

Vitiligo is a dreaded disease in India due to its disfiguring nature and stigmatization. We describe a woman who had accidental burns during home treatment with PUVA. She had an underlying atopic diathesis. The burns healed leaving severe prurigo nodularis, which caused crippling pruritus. To the best of our knowledge, this is the first time prurigo nodularis has been reported in the dermatologic literature as a complication of accidental PUVA burns in a vitiligo patient.

\section{CASE REPORT}

A 50-year-old woman presented to this clinic with severely pruritic nodules and plaques on her legs and breasts. She developed vitiligo at the age of 18 years and had been unsuccessfully treated with many drugs. In 1991, she was treated with home psoralen plus ultraviolet-A radiation (PUVA), using $20 \mathrm{mg}$ of oral methoxsalen. The light source used was a set of 4 tube lights of $100 \mathrm{~W}$, emitting UVA with wavelengths between 315 and $350 \mathrm{~nm}$, and she exposed the affected areas for three minutes three times a week. Within about 5 months, there was marked improvement of the vitiligo lesions on her legs and also total clearing of the lesions on her face, except for the ones on the lips. Around this time, she accidentally fell asleep during her PUVA sessions and woke up 60 minutes later with blistering burns on her breasts and legs, which took a month to heal. During the healing stage, she started developing thickened skin, nodules and plaques on her legs and breasts, which were intensely itchy. She was given emollients, topical steroids, antihistamines, individually and in combination, with little benefit. Many nodules coalesced to form scaly

Received on 29.11.2011.

Approved by the Advisory Board and accepted for publication on 15.03.2012

* Work conducted at Nirvana Skin Clinic - Vadodara, India.

Conflict of interest: None

Financial funding: None

MBBS, DV\&D, FRCP (Lon.) - Consultant dermatologist, Nirvana Skin Clinic - Vadodara, India.

MD - Academic Teaching Hospital Dresden-Friedrichstadt, Department of Dermatology and Allergology - Dresden, German

(C)2012 by Anais Brasileiros de Dermatologia 
plaques. Then, her homeopath husband started treating her with some homeopathic medication, which apparently caused resolution of the lesions for many years. The lesions only reappeared in 2004 . Several physicians and dermatologists diagnosed her condition as psoriasis and post-burn keloids. She was prescribed oral steroids by a private practitioner for a few months, which was later stopped as she developed diabetes. She now has excruciating itching, which has severely affected her quality of life.

On examination, she had vitiligo on her breasts and lower limbs, showing perifollicular pigmentation. Her legs were studded with thick, horny, hyperkeratotic nodules with a rough surface, many of them coalescing to form plaques on the anterior aspect (Figure 1). She had severely pruritic erythematous nodules on the breasts (Figure 2). The skin on her face, abdomen, back and upper limbs was normal. She was diabetic, hypothyroid and took metformin and thyroxine daily. Her blood work up and serum chemistry were normal, except for an IgE level of $700 \mathrm{IU} / \mathrm{ml}$, with no history, signs or symptoms of atopy such as chronic itching, eczema, allergic rhinitis or asthma. She, however, had a family history of eczema and allergic rhinitis. A skin biopsy taken from the nodule showed a superficial perivascular lymphocytic infiltrate with moderate irregular epidermal hyperplasia. The papillary dermis was thickened with papillomatosis and showed thickened bundles of collagen in a vertical array. The capillaries in the papillary dermis were increased in number and thick-walled. The granular layer was thickened and the stratum corneum showed marked compact orthokeratosis (Figure 3). One of the sections

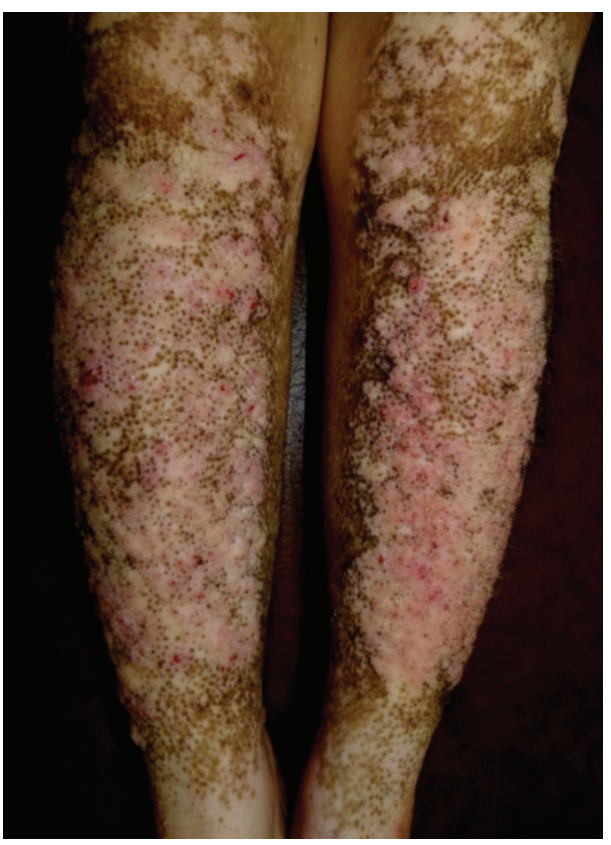

FIGURE 1: Multiple coalescing erythematous excoriated nodules on both legs

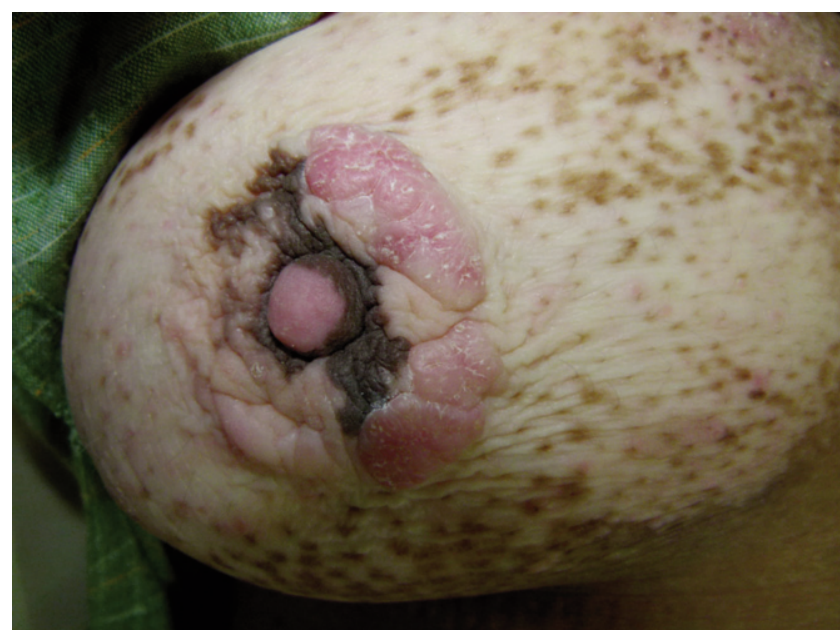

FIGURE 2: Erythematous nodules on vitiliginous skin on her breast

showed abundant deposit of amyloid in the papillary dermis. The histological diagnosis was prurigo nodularis (PN) associated with lichen amyloidosis (Figure 3). We started her on $900 \mathrm{mg}$ of gabapentin with topical halobetasol and petrolatum, and she reported a relief of about $20 \%$ of her itching in 30 days.

\section{DISCUSSION}

We report a case of prurigo nodularis occurring on the sites of PUVA burns in a vitiligo patient. Oral PUVA, which is one of the most common treatment modalities for India's millions of vitiligo patients, has side effects that may be short-term or long-term. Short-term adverse effects include erythema, swelling, dry skin, pruritus, axillary freckling, increased recur-

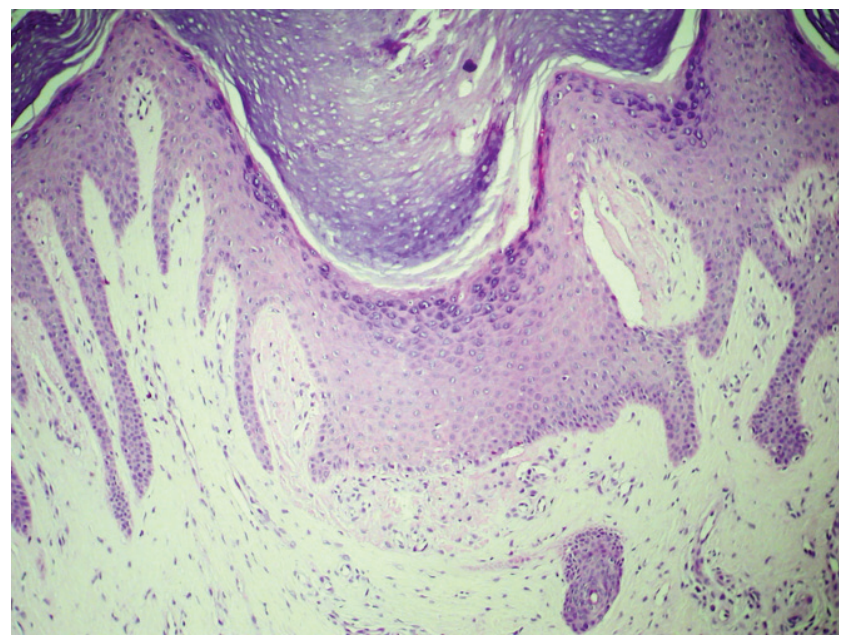

FIGURE 3: Massive hyperorthokeratosis associated with hypergranulosis and acanthotic epidermis with saw-tooth-like proliferations. Focal basal cell degeneration and a mild lymphocytic inflammatory infiltrate in the dermis. (H\&E 40X) 
rence of herpes simplex virus and, rarely, phototoxic blisters. Possible long-term adverse effects are accelerated skin ageing with wrinkle formation, telangectasias, lentigines, elastosis, xerosis and pigmentary changes. ${ }^{1}$ High cumulative PUVA exposure is associated with a dose-related increase in the risk of nonmelanoma skin cancer, particularly genital and cutaneous squamous cell carcinoma, in Caucasians only. ${ }^{2}$ However, nodular prurigo has never been reported.

Accidental burns during photochemotherapy have been reported too, including burns during selftreatment, as seen in this patient. ${ }^{3,4}$ Bothersome pruritus following burns per se is a known phenomenon, though there is a paucity of long-term prospective studies documenting the course and magnitude of this phenomenon. ${ }^{5,6}$ Burns are known inducers of neuropathic itch. A study by Van Loey et al. documented itching at 3,12 and 24 months after burns and recorded mild to severe itching in $87 \%, 70 \%$ and $67 \%$ of patients. ${ }^{6}$ However, this appears to be the first case of prurigo nodularis developing after accidental PUVA burns. We propose the following logical sequence. Vitiliginous skin is more prone to burns. The accidental PUVA burns due to gross overdose initiated the itch in this patient, who also had atopic diathesis, indicated by a high level of serum IgE, and a family history of eczema and allergic rhinitis. Itching is known to induce hyperplastic cutaneous response, and this probably would have lead to the development of prurigo nodularis $(\mathrm{PN})$ in this patient. There is a report of a bomb blast injury causing prurigo nodu-

\section{REFERENCES}

1. Abdel Naser MB, Wollina U, El Okby M, El Shiemy S. Psoralen plus ultraviolet A irradiation-induced lentigines arising in vitiligo: Involvement of vitiliginous and normal appearing skin. ClinExpDermatol. 2004;29:380-2 .

2. Murase JE, Lee EE, Koo J. Effect of ethnicity on the risk of developing nonmelanoma skin cancer following long-term PUVA therapy. Int J Dermatol. 2005;44:1016-21.

3. Herr H, Cho HJ, Yu S. Burns caused by accidental overdose of photochemotherapy (PUVA). Burns. 2007:33:372-5

4. Sulliman MT, Abdolmoneim M. Severe burns following phototherapy with PUVA for vitiligo: A preventable complication that is still happening. Burns. 2005;31:1063

5. Goutos I, Dziewulski P, Richardson PM. Pruritus in burns: Review article. J Burn Care Res. 2009;30:221-8.

6. Van Loey NE, Bremer MK, Faber AW, Middelkoop E, Nieuwenhuis MK. Itching following burns: Epidemiology and predictors. Br J Dermatol. 2008;158:95-100.

7. Ghosh SK, Bandyopadhyay D, Ghosh A, Sarkar S, Mandal RK. Prurigonodularislike skin eruptions after bomb-blast injury. ClinExpDermatol. 2009;34:e471-2.

8. Weigelt N, Metze D, Ständer S. Prurigonodularis: Systematic analysis of 58 histological criteria in 136 patients. J Cutan Pathol. 2010;37:578-86.

9. Schuhknecht B, Marziniak M, Wissel A, Phan NQ, Pappai D, Dangelmaier J, et al. Reduced intraepidermal nerve fibre density in lesional and nonlesional prurigonodularis skin as a potential sign of subclinical cutaneous neuropathy. $\mathrm{Br} J$ Dermatol. 2011;165: 85-91. laris-like lesions. ${ }^{7}$ The diagnosis of prurigo nodularis is based upon family and personal history, typical clinical presentation and distribution of the lesions along the cleavage lines (Langer's lines) of the skin and is confirmed by histopathology. The amyloid deposit seen in some sections could be due to the chronic scratching in PN.

Highly characteristic of $\mathrm{PN}$ is the presence of thick compact orthohyperkeratosis; the hairy palm sign (folliculosebaceous units in nonvolar skin in conjunction with a thick and compact cornified layer, like that of volar skin); irregular epidermal hyperplasia or pseudoepitheliomatous hyperplasia; focal parakeratosis; hypergranulosis; fibrosis of the papillary dermis with vertically arranged collagen fibers; increased number of fibroblasts and capillaries; a superficial, perivascular and/or interstitial inflammatory infiltrate of lymphocytes, macrophages and, to a lesser extent, eosinophils and neutrophils. ${ }^{8}$ Histological analysis of lesional and nonlesional skin in PN has demonstrated reduced density of nerve endings, findings suggesting a cutaneous neuropathy.' Interestingly, the itch induced by burns, which would have played a major role in the development of $\mathrm{PN}$, is also neuropathic in origin. ${ }^{5}$ The rationale of using gabapentin is that it has been tried with varying success in both burn-induced itching and PN. 5,10,11

We believe we are reporting the first case of accidental PUVA burns developing prurigo nodularis in a woman with atopic diathesis in the dermatologic literature.
10. Gencoglan G, Inanir I, Gunduz K. Therapeutic hotline. Treatment of prurigonodularis and lichen simplex chronicus with gabapentin. DermatolTher. 2010;23:194-8

11. Ahuja RB, Gupta R, Gupta G, Shrivastava P. A comparative analysis of cetirizine, gabapentin and their combination in the relief of post-burn pruritus. Burns 2011:37: 203-7.

\author{
MAILING ADDRESS: \\ Shyam Bhanushankar Verma \\ 18 AmeeSociety - Diwalipura \\ Vadodara 390 015, INDIA \\ E-mail: skindiaverma@gmail.com \\ Phone: +912652323838
}

How to cite this article: Verma SB, Wollina U. Accidental PUVA burns, vitiligo and atopic diathesis resulting in prurigo nodularis: a logical but undocumented rarity. An Bras Dermatol. 2012;87(6):891-3. 